DOI 10.37882/2223-2974.2020.10.22

\title{
ИНСТИТУЦИОНАЛЬНЫЕ ФАКТОРЫ И ОСОБЕННОСТИ РАЗВИТИЯ ИННОВАЦИОННОГО ПРЕДПРИНИМАТЕЛЬСТВА В РОССИЙСКОЙ ФЕДЕРАЦИИ
}

\section{INSTITUTIONAL FACTORS AND FEATURES OF THE DEVELOPMENT OF INNOVATIVE ENTREPRENEURSHIP IN THE RUSSIAN FEDERATION}

Muthanna Ali Salem Ali

Summary: The article researches innovative factors for the development of the functioning of innovative entrepreneurship in the Russian Federation. Legal, material, financial, intellectual factors were considered, as well as state support for features of the development of innovative entrepreneurship in the Russian Federation.

Keywords: entrepreneurship; innovations; institutes; innovative business.

\author{
Мутхана Али Салем Али \\ Самарский государственный экономический \\ университет «СГЭУ» \\ ali.muthanna7@gmail.com
}

Аннотация: В статье исследованы инновационные факторы развития функционирования инновационного предпринимательства в Российской Федерации. Рассмотрены правовые, материальные, финансовые, интеллектуальные факторы, а также государственная поддержка особенностей развития инновационного предпринимательства в Российской Федерации.

Ключевые слова: предпринимательство; инновации; институты; инновационное предпринимательство.

- формирование нового сектора рынка;

- формирование и осуществление продуктовых, профессиональных, общественных, научно-технических, промышленных инноваций;

- преобразование концепции управления;

- институционализация инновационной работы, осваивание в этих целях новейших источников сырья и рынков сбыта.

В основе формирования инновационной активности лежат информационно-коммуникационные технологические процессы [5].

Отталкиваясь из того, что осуществление инноваций направлено не только лишь на формирование определенной экономической организации, однако и на увеличение социально-экономической производительности становления государства, следует вводить надлежащие институциональные коррективы, которые считаются институциональными преобразованиями, позволяющими устанавливать отличия от стратегической цели и устанавливать траекторию формирования интегрированной компании [3], очертания управления ею [5].

Далее рассмотрим перспективы инноваций в Российской Федерации в сравнении по годам за 2013 и 2020 гг.

В Российской Федерации была выстроена структура финансовой поддержки инноваций в предпринимательской области, которая выглядит следующим образом. 
Таблица 1.

Институциональные факторы становления инновационной деятельности [2]

\begin{tabular}{|c|c|c|}
\hline Институциональные факторы & Характеристика & Реализация \\
\hline $\begin{array}{l}\text { Государственная поддержка } \\
\text { инновационной деятельности }\end{array}$ & $\begin{array}{l}\text { На федеральном уровне: Создание особых экономических } \\
\text { зон (технико-внедренческие зоны), инновационные про- } \\
\text { екты и социально-экономические программы. }\end{array}$ & $\begin{array}{l}\text { Формирование и развитие технико-внедренческих зон, } \\
\text { внутри которых размещаются научно-исследовательские, } \\
\text { проектные, конструкторские бюро и организации. Созда- } \\
\text { ние и функционирование научно-технических центров, } \\
\text { венчурных компаний и т.п. Финансирование инновацион- } \\
\text { ной деятельности, залоговые и гарантийные фонды. }\end{array}$ \\
\hline Правовые & $\begin{array}{l}\text { Федеральные законы, Указы Президента Российской Феде- } \\
\text { рации, Постановления Правительства Российской Федера- } \\
\text { ции, региональные нормативные правовые акты и т.д. }\end{array}$ & $\begin{array}{l}\text { Создание нормативной правовой базы развития иннова- } \\
\text { ционной активности }\end{array}$ \\
\hline Финансовые & $\begin{array}{l}\text { Инвестиционные проекты. Финансовый лизинг. Фандрай- } \\
\text { зинг. Субсидии, иные финансовые формы государственной } \\
\text { поддержки. Механизмы государственно-частного пар- } \\
\text { тнёрства. }\end{array}$ & $\begin{array}{l}\text { Поиск финансовых источников и привлечение финансо- } \\
\text { вых средств. Повышение эффективности использования } \\
\text { собственных средств. Эффект финансового рычага (леве- } \\
\text { риджа). }\end{array}$ \\
\hline Материальные & Материальные ресурсы: основные и оборотные средства & $\begin{array}{l}\text { Обновление основных фондов. Пополнение оборотных } \\
\text { средств. Предоставление зданий, помещений на условиях } \\
\text { аренды и т.д. }\end{array}$ \\
\hline Интеллектуальные & $\begin{array}{l}\text { Развитие инфраструктуры институционально-инноваци- } \\
\text { онных центров. }\end{array}$ & $\begin{array}{l}\text { Создание технопарков, научных и инновационно-техно- } \\
\text { логических центров, технопарков, технополисов, бизнес- } \\
\text { инкубаторов, научно-исследовательских институтов и т.д. }\end{array}$ \\
\hline
\end{tabular}

Таблица 2.

Перспективы инноваций в России, 2013-2020 гг. [4]

\begin{tabular}{|l|c|c|}
\hline \multicolumn{1}{|c|}{ Показатели } & 2013 г. & 2020 г. \\
\hline Госрасходы на НИОКР, \% ВВП & 0,76 & 1,27 \\
\hline Частные инвестиции в НИОКР, \% ВВП & 0,37 & 1,71 \\
\hline Баланс торговли интеллектуальной собственностью, \% ВВП & $-0,38$ & 0,03 \\
\hline Доля высокотехнологического экспорта, \% от оборота в мире & 0,4 & 2 \\
\hline Доля компаний, инвестирующих в инновации, \% от компаний в стране & 9 & 25 \\
\hline
\end{tabular}

1. Российский фонд прямых инвестиций (РПФИ). Занимает верхнюю позицию пирамиды. Резерв фондового капитала - 10 млрд долларов. Главная цель - выступление в значимости соинвестора с целью международных компаний, инвестирующих средства в экономику Российской Федерации. Проанализируем такую ситуацию. В рамках масштабного бизнеса данный инструмент крайне функционален. Взаимодействие с отечественным фондом идет непосредственно, с организацией встреч, а инвестиционные решения принимаются советами различного уровня.

2. «Роснано». Соответствующую ступень пирамиды представляет фонд отечественных нанотехнологий с бюджетом, насчитывающим на 2015 г. приблизительно 100 миллиардов руб., однако цифры изменяются. Он владеет сильным экономическим потенциалом для эффективных вложений в малый и средний бизнес, то, что имеет важность для долговременных возможностей.
3. Российская венчурная компания. Основная цель финансирование технологических компаний и команд для формирования венчурного рынка инвестиций.

4. Фонд развития промышленности. Основная цель - софинансирование инвестиционных проектов.

5. «Сколково». Деятельность не отличается от единой системы. Что касается финансирования бюджета, в таком случае на 2015 г. оно равняется приблизительно 40 миллиардов руб. Специализация - поддержка инфраструктуры проектов, сформированных на основе научно-исследовательских и экспериментально-конструкторских работ. Поддержку получают компании - резиденты «Сколково». Формируются проекты с целью их последующего выхода на зарубежный рынок. Средства выделяется сравнительно небольшое число - от 1-5 максимально до 30 миллионов руб. Завершающая стадия продвижения предполагает 
независимое нахождение бизнесом инвестора.

6. Корпорация малого и среднего предпринимательства (далее - МСП). Вид поддержки - обеспечение гарантий по кредитам, выдаваемым банковскими организациями. Поддержка запрашивается через сайт. МСП взаимодействует с небольшими и средними предприятиями через партнерские банки, которых насчитывается 150. Поиск определенной региональной компании реализовывают на банковском сайте в области о получении помощи.

7. Фонд содействия инновациям (далее - Фонд). Фонд способствует формированию малых форм предприятий в научно-промышленной сфере. Это одна из наиболее действующих организаций, выделяющая средства на поддержку стартапов.

При этом отметим, что вышеуказанные фонды обладают федеральным статусом. Однако бизнесу будет не лишним, кроме того, акцентировать внимание на инструментах, существующих в распоряжении субъектов Российской Федерации.

В течение последних лет была создана нормативноправовая база для обеспечения реализации мер государственной поддержки инновационной деятельности предпринимателей. Согласно действующему законодательству, субъекты Российской Федерации и органы государственной власти субъектов Российской Федерации может оказывать иные формы поддержки, которые не предусмотрены федеральным законодательством. Самое главное условие, не противоречие законодательству Российской Федерации. В Самарской области предусматривается долевое участие в уставном капитале юридических лиц, осуществляющих инновационную деятельность.

При этом считаем, что в настоящее время содействие инновационному развитию предпринимательства обеспечивается за счет: программ поддержки в отношении инновационных территориальных кластеров, работы центра «Сколково», кооперациями вузов и предприятий в соответствии с Постановлением со стороны правительства № 218, создания технопарков, программ от Фонда содействия инновациям, проектов и фондов от «Роснано», займов от Фонда развития предпринимательства, строительства инновационной инфраструктуры с целью обеспечения инновационной деятельности предприятий в области малого и среднего бизнеса.

Таким образом, институциональное обеспечение инновационной активности обязано позволять разным финансовым структурам формировать многофункциональную основу для последующей реализации запланированных ориентиров в течение инновационного становления. При этом главными элементами многофункционального обеспечения инновационных процессов, осуществляемых организациями, считаются профессиональное, информационное, институциональное, экономическое и инфраструктурное предоставление. Современное обеспечение обязано содействовать реализации запланированных целей деятельности компании с помощью рационализации принимаемых управленческих заключений на абсолютно всех стадиях осуществления инновационной деятельности при оптимизации затрачиваемых средств. Неоднократно, Счетная палата Российской Федерации в своих заключениях сообщала об неэффективности использования и расходования бюджетных средств в указанной сфере.

Считаем, что необходимо провести аудит деятельности институтов развития, которые оказываются финансовому, консультативную поддержку организациям в инновационной сфере. Основная цель аудита - это выявление дублирующих задач и функций институтов развития для возможности их оптимизации.

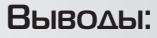

1. исследованы инновационные факторы развития функционирования инновационного предпринимательства в Российской Федерации.

2. Рассмотрены правовые, материальные, финансовые, интеллектуальные факторы, а также государственная поддержка инновационных особенностей развития инновационного предпринимательства в Российской Федерации.

\section{ЛИТЕРАТУРА}

1. Ефременко В.Ф., Бахарев С.М. Динамика развития инновационной инфраструктуры в региональных инновационных системах Дальневосточного федерального округа Российской Федерации // Власть и управление на Востоке России. - 2019. - № 1 (86). - С. 41-50.

2. Инновационное предпринимательство: опыт регионов: материалы Международной научно-практической конференции, 18-19 мая 2018 г. [Текст] / редкол.: К.К. Полянский [и др.]. - Воронеж: Издательско-полиграфический центр «Научная книга», 2018. - 259 с.

3. Кравец А.В., Кашин А.В. Экономическое взаимодействие государства и бизнеса как условие формирования инновационного предпринимательства в России // Креативная экономика. - 2016. - Т. 10. - № 2. - С. 161-172.

4. Оициальный сайт Правительства Российской Федерации. URL: http://government.ru (дата обращения: 31.08.2020).

5. Хетагурова Ю.И. Особенности развития инновационного предпринимательства в РФ // Экономика: вчера, сегодня, завтра. - 2018. - Том 8. - № 8А. C. 142-150. 